Research Articles

\title{
Biocompatibility of Orthodontic Resins: In vitro Evaluation of Monomer Leaching and Cytotoxic Effects
}

\author{
$1,2^{*}$ Roberto Uomo, ${ }^{2 *}$ Gianrico Spagnuolo, ${ }^{3}$ Giuseppina Nocca, \\ ${ }^{1}$ Angela Galeotti, ${ }^{2}$ Ambrosina Michelotti, ${ }^{2}$ Rosa Valletta and ${ }^{1,2}$ Vincenzo D'Antò \\ ${ }^{I}$ Division of Dentistry, Department of Pediatric Surgery, \\ Bambino Gesù Children's Hospital, Piazza Sant'Onofrio $n^{\circ} 4,00146$, Rome, Italy \\ ${ }^{2}$ Department of Neurosciences, Reproductive Sciences and Oral Sciences, \\ University of Naples "Federico II", Via Pansini n ${ }^{\circ}$, 80131, Naples, Italy \\ ${ }^{3}$ Institute of Biochemistry and Clinical Biochemistry, \\ Catholic University of Sacred Heart, Largo Francesco Vito 1, 00168 Rome, Italy
}

Article history

Received: 26-06-2017

Revised: 03-07-2017

Accepted: 07-07-2017

\section{Corresponding Author:}

Gianrico Spagnuolo

Department of Neurosciences,

Reproductive Sciences and Oral

Sciences, University of Naples

"Federico II," Via Pansini n5,

80131, Naples, Italy

Tel: +390817462080

Email: gianrico.spagnuolo@gmail.com

*These authors contributed equally to this work

\begin{abstract}
The aim of this study was to investigate the effect of orthodontic resins on cell survival and to evaluate monomer leaching both before and after resin polymerization. Materials and methods: 3T3 mouse fibroblasts were exposed to three cured and uncured orthodontic resins. Cellular viability was assessed by Alamar Blue assay after 24,48 and $72 \mathrm{~h}$. High Performance Liquid Chromatography was used to measure the amount of monomers released by the tested samples. Data were analyzed by means of ANOVA and Tukey's test $(p<0.05)$. All tested materials exerted a cytotoxic response. Cytotoxicity tests showed that the uncured samples were more cytotoxic than the polymerized ones. A time-dependent reduction in cellular viability was found. Monomer release analyses indicated a higher elution of Triethylene Glycol Dimethacrylate (TEGDMA) compared to Bisphenol A Glycidyl Methacrylate. TEGDMA release was higher in the uncured samples and showed a time-dependent pattern. Our results showed the role of resin curing in determining the cytotoxic effect of orthodontic resins and suggested that the differences in the chemical composition of resin matrix appeared to be much more related to the decrease in cell viability than the amount of monomer leaching from orthodontic resins. Clinicians should pay greater attention to resin curing after bracket placement in order to reduce the potentially dangerous effect of monomer release.
\end{abstract}

Keywords: Biocompatibility, Composite Resins, Orthodontics, Monomer Elution

\section{Introduction}

The introduction of the acid etch technique by Buonocore (1955) and the direct bonding bracket by Newman (1992) revolutionized the orthodontic clinical practice using Resin-Based Adhesively bonded Materials (RBDM). Since then, their use has widely increased owing to numerous advantages for patients and clinicians, including shorter bonding sessions, aesthetics, reduction in discomfort and gingival irritation (Jonke et al., 2008).

Orthodontic composites and adhesives are made up of two main monomers: Bisphenol A diglycidyl dimethacrylate (Bis-GMA) and Triethylene Glycol
Dimethacrylate (TEGDMA). The former is characterized by higher molecular weight, size and hydrophobicity compared to the latter (Geurtsen, 1998).

Incomplete RBDM conversion and/or their degradation in the oral environment causes the release of monomers which may affect adjacent tissues (Jagdish et al., 2009; Gioka et al., 2005). Light-cured or chemically cured dental composite resins leave a soft, sticky superficial layer upon polymerization, commonly referred to as an Oxygen-Inhibited Layer (OIL) because of its origin (Suh, 2004). In orthodontic clinical practice, this can concern the bonding agents around the bracket base.

The elution process depends on the size, the weight and the chemical composition of the leachable 
molecules. Unlike the bulky basic and large monomers such as Bis-GMA, TEGDMA molecules leach out faster into the aqueous oral environment (Tanaka et al., 1991).

Resin dental monomers were found to be cytotoxic and the tests all indicated damages to cell membrane integrity and alteration of cell functions, such as enzyme activities or synthesis of macromolecules (Schweikl et al., 1998). In vitro studies revealed that TEGDMA caused a dose-dependent mutagenic effect in mammalian cells inducing formation of micronuclei, cell cycle delay and apoptosis via Reactive Oxygen Species (ROS) production (Schweikl et al., 2001; Eckhardt et al., 2009a). Furthermore Bis-GMA and TEGDMA reduced the levels of the radical scavenger glutathione (GSH), which protects cell structures from damage caused by oxidative stress (Schweikl et al., 2006). Depletion of the intracellular GSH pool may increase ROS levels leading to cell death through necrosis or apoptosis (Spagnuolo et al., 2013; Heil et al., 1996).

TEGDMA monomers may influence specific cell responses of the innate immune system (Eckhardt et al., 2009b). Moreover, Bis-GMA resulted positive in the DNA synthesis inhibition test (Yano et al., 2011) and direct exposure to high concentrations induced apoptosis (Franz et al., 2003).

Several studies investigated the cytotoxic effects of various RDBM used in operative dentistry (Schweikl et al., 2005), while there are few data regarding orthodontic resin materials and their biological properties. Recently, the cytotoxicity of orthodontic primers (D'Antò et al., 2009) and composites (Malkoc et al., 2010) has been demonstrated, but no research focus on the relationship between toxicity and monomers elution rate. Therefore, the purpose of our study was to assess the cytotoxicity of three conventional orthodontic composites, correlating their cytotoxic effects to the analysis of monomer elution before and after polymerization.

\section{Materials and Methods}

\section{Cell Cultures}

$3 \mathrm{~T} 3$ mouse fibroblasts were grown in a $5 \% \mathrm{CO}_{2}$ atmosphere at $37^{\circ} \mathrm{C}$, in Dulbecco's Modified Eagle Medium (DMEM) with 4-(2-hydroxyethyl)-1- piperazineethanesulfonic acid (HEPES, $10 \mathrm{mM}$ ), glucose (1.0 $\left.\mathrm{g} \mathrm{L}^{-1}\right), \mathrm{NaHCO}_{3}\left(3.7 \mathrm{~g} \mathrm{~L}^{-1}\right)$, penicillin (100 units $\left.\mathrm{mL}^{-1}\right)$, streptomycin $\left(100 \mathrm{mg} \mathrm{mL}^{-1}\right)$ and $10 \%$ fetal calf serum. Reagents and cells were purchased from Lonza (Treviglio, Italy).

\section{Test Materials and Samples Preparation}

The orthodontic composites tested in this study were Transbond XT (3M Unitek, Monrovia, USA), Eagle Spectrum (American Orthodontics, Sheboygan, USA) and Greengloo (Ormco Europe, Glendora, USA) (Table 1).

Resin specimens were stratified in uniform-size samples (6 $\mathrm{mm}$ in diameter and $2 \mathrm{~mm}$ in height) into cell culture inserts (Fig. 1), with $8 \mu \mathrm{m}$ size pore membrane filters (Corning Costar Transwell cell culture inserts, Corning Incorporated, NY, USA), under aseptic conditions to limit the influence of biologic contamination on the cell culture tests. All composites were analyzed as both cured and uncured specimens. Specimens that required light curing were polymerized with the maximum time recommended by the manufacturer (Table 1) by a LED light curing unit (wavelength range: $430-480 \mathrm{~nm}$; light intensity: Approx. $1000 \mathrm{~mW} / \mathrm{cm}^{2}$; Elipar FreeLight 2, 3M ESPE Dental Products, St Paul, Minn).

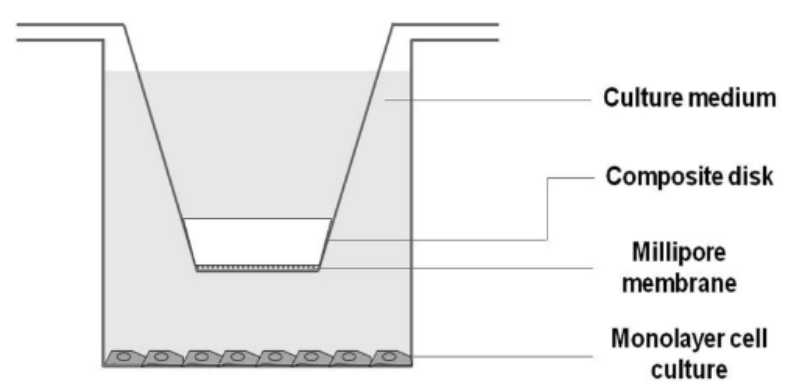

Fig. 1. Schematic illustration of Transwell assay used. Resin specimens were stratified into cell culture inserts, with 8 $\mu \mathrm{m}$ size pore membrane filters, under aseptic conditions to limit the influence of biologic contamination on the cell culture test. Cell monolayers were seeded in the lower chambers of the tissue culture plates. Cell culture with inserts without test materials were used as a negative control

Table 1. Tested orthodontic composites

\begin{tabular}{|c|c|c|c|c|}
\hline Material & Manufacturer & Batch number & $\begin{array}{l}\text { Suggested curing } \\
\text { time (seconds) }\end{array}$ & Composition \\
\hline Eagle Spectrum & $\begin{array}{l}\text { American Orthodontics, } \\
\text { Sheboygan, WI, USA }\end{array}$ & 001-940/001-945 & $5-10$ & $\begin{array}{l}\text { Bis-GMA, TEGDMA, Ethoxylated bisphenol } \\
\text { A dimethacrylate, inorganic filler, camphoroquinone }\end{array}$ \\
\hline Greengloo & $\begin{array}{l}\text { Ormco Corporation, } \\
\text { Orange, CA, USA }\end{array}$ & $\begin{array}{l}740-0320 / 740- \\
0322\end{array}$ & $10-30$ & $\begin{array}{l}\text { TEGDMA, Ethyloxylated trimethylopropane triacrylate, } \\
\text { Ethoxylated bisphenol A dimethacrylate, inorganic } \\
\text { filler, camphoroquinone }\end{array}$ \\
\hline Transbond XT & $\begin{array}{l}\text { 3M Unitek Ortho Prod, } \\
\text { Monrovia, CA, USA }\end{array}$ & $712-030 / 712-036$ & $10-20$ & $\begin{array}{l}\text { Bis-GMA, silane, n-dimethylbenzocaine, phosphorus } \\
\text { hexafluoride, inorganic filler, camphoroquinone }\end{array}$ \\
\hline
\end{tabular}

Tested materials: Composition of materials (information obtained from the manufacturers). Suggested curing times for each resin is reported according to the manufacturer's recommendation 


\section{Cell Viability}

Cytotoxicity of cured and uncured orthodontic composites were evaluated by Alamar Blue (AB) staining (Biosource Internation, Camarillo, CA) in order to measure the influence of tested materials on cell viability (Borra et al., 2009). Cells were seeded in the lower chambers of a 24 trans well tissue culture plate (Costar, Corning Incorporated, NY, USA) at $20 \times 10^{3}$ cells/well density in $2 \mathrm{~mL}$ of complete medium. Cell culture with inserts without test materials were used as a negative control.

After a $24 \mathrm{~h}$ exposure for uncured samples and 24, 48 and $72 \mathrm{~h}$ for cured samples, the AB assay was performed according to the manufacturer's protocol. The optical density was measured at wavelength between 540 and $590 \mathrm{~nm}$ by using a plate reader spectrophotometer (Sunrise, TECAN, Männedorf, Zurich, Switzerland) and the percent of $\mathrm{AB}$ reduction was calculated using the manufacturer formula.

\section{Monomer Leaching Evaluation}

High Performance Liquid Chromatography (HPLC) technique was used in our study in order to determine the amount of Bis-GMA and TEGDMA leached from cured and uncured samples.

The same types of cured and uncured specimens used for cell cultures were incubated for 24, 48 and 72 $\mathrm{h}$ in $2 \mathrm{~mL}$ of DMEM. The media were then centrifuged and filtered through a $0.45 \mu \mathrm{m}$ syringe filter (Whatman, Maidstone Kent, UK), the residue precipitated in each tube was suspended again with $300 \mu \mathrm{L}$ of acetonitrile $\left(\mathrm{CH}_{3} \mathrm{CN}\right)$, then $300 \mu \mathrm{L}$ of filtered media were added. Lastly, samples were heated to $37^{\circ} \mathrm{C}$ for $5 \mathrm{~min}$, centrifuged at $15000 \mathrm{~g}$ for 5 min and diluted 1:10 in $\mathrm{CH}_{3} \mathrm{CN}$. Samples were then analyzed using a JASCO HPLC system (2 PU-980 pumps, UV-970 UV/VIS detector and AS-1555 auto sampler). The analyses were performed at a wavelength of $214 \mathrm{~nm}$ with a C-18 $(5 \mu \mathrm{m})$ Supelco reversed phase column $(250 \times 4.6 \mathrm{~mm})$ using an elution gradient of water (A) and methanol (B) starting from 50 to $30 \%$ of A (10 min) and to $15 \%$ of A (5 min), 0.7 $\mathrm{mL} \min ^{-1}$ flow, $50 \mu \mathrm{L}$ injected volume.

The concentration of TEGDMA and Bis-GMA in each sample was quantified using a calibration line performed with standard solutions (Sigma Aldrich, Milan, Italy) before and after each analysis.

\section{Statistical Analysis}

Individual values were summarized as means $\pm \mathrm{SD}$ from independent experiments $(n=4)$ and the data were analyzed by one-way Analysis Of Variance (ANOVA) followed by Turkey's test for multiple comparisons.

The level of significance was set at $\mathrm{p}<0.05$.

\section{Results}

\section{Cytotoxicity of Tested Materials}

Cytotoxicity of cured and uncured orthodontic composites, evaluated by $\mathrm{AB}$, showed that the percentages of cell viability at $24 \mathrm{~h}$ after exposure were lower than in controls: Uncured composites were significantly more cytotoxic than cured (Fig. 2). Greengloo showed the highest percentages of reduction in cell viability, both before and after polymerization, between the tested materials (Fig. 2).

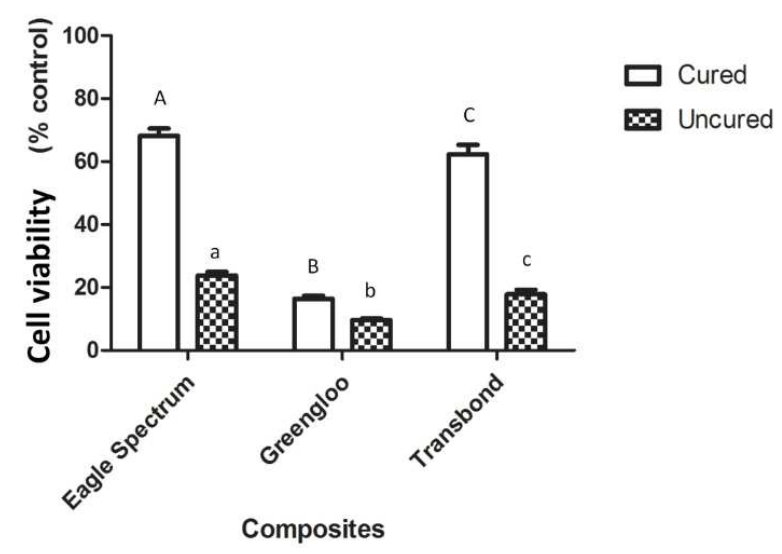

Fig. 2. Cell survival rates after $24 \mathrm{~h}$ exposure to cured and uncured orthodontic resins. Results are reported as a percentage of negative controls (mean $\pm \mathrm{SD}$ ). Different case of the same letter indicates significant difference among cured and uncured sample of the same composite. Different capital or small letters indicate difference among cured or uncured composites respectively $(\mathrm{p} \leq 0.05)$.

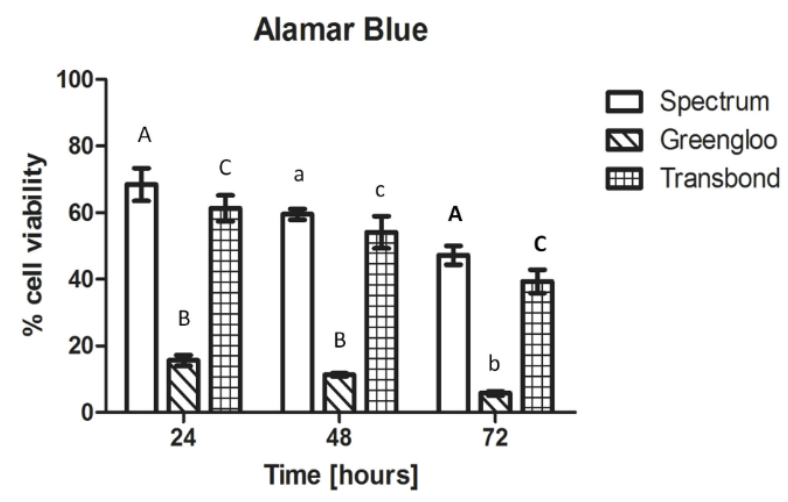

Fig. 3. Cell viability, evaluated after 24,48 and $72 \mathrm{~h}$ exposure to cured orthodontic composites. Results represent means \pm SD. Different letters indicate statistically significant difference among resins within the same timepoint. Different style (upper case, lower case, upper bold case) of the same letter indicates statistical significant difference of samples of the same resin between different timepoints 

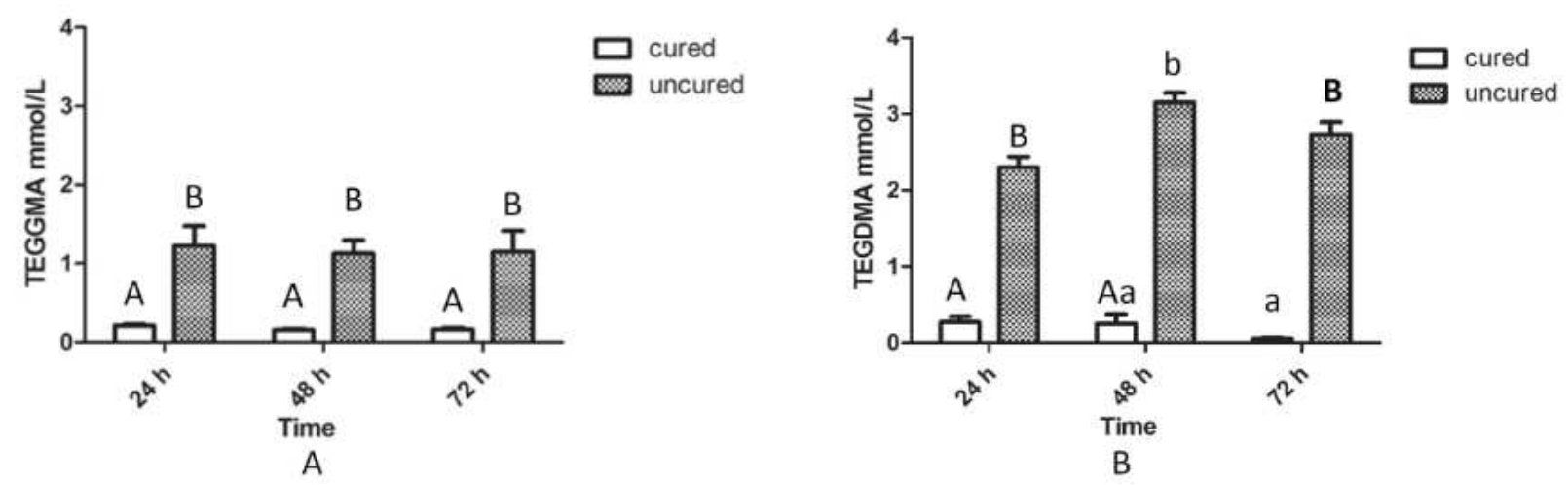

Fig. 4. Cumulative TEGDMA monomer leaching from Eagle Spectrum (A) and Greengloo (B) eluates after 24, 48 and 72 h. Letters shared in common between or among the columns would indicate no significant difference

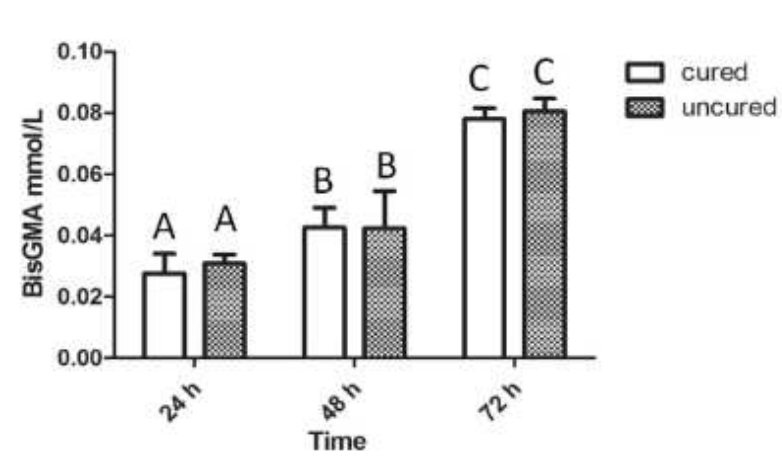

A

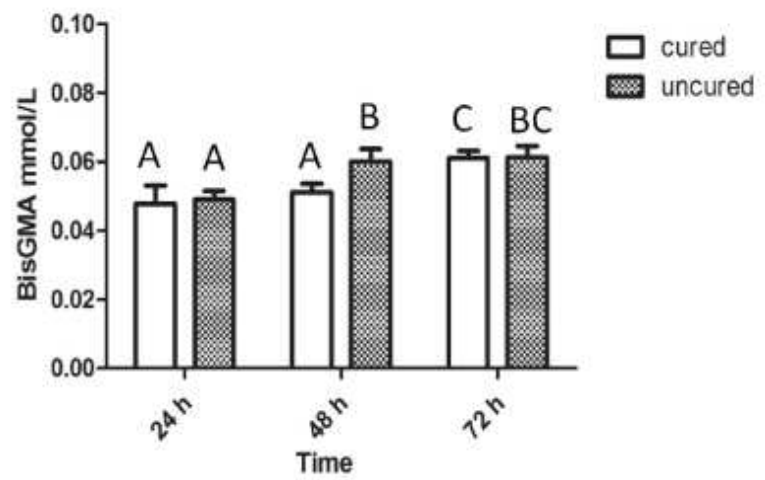

B

Fig. 5. Cumulative Bis-GMA monomer leaching from Eagle Spectrum (A) and Transbond XT (B) eluates after 24, 48 and $72 \mathrm{~h}$ (A) Different letters indicate statistically significant difference in Bis-GMA release between timepoints for the cured and uncured sample respectively. No difference was found between the release in cured and uncured specimen within the same timepoint $(p \leq 0.05)$. (B) Letters shared in common between or among the columns would indicate no significant difference $(p \leq 0.05)$.

All cured materials showed a significant decrease in cell survival rates compared to the control group and a time dependent cytotoxic effect resulted for all the tested materials (Fig. 3). Greengloo exerted the highest cytotoxic effect at 24, 48 and $72 \mathrm{~h}$ between tested resins even if no statistical difference was found between eluates at 24 and $48 \mathrm{~h}$ (Fig. 3).

\section{HPLC Results}

Bis-GMA signals were found in Transbond XT and Eagle Spectrum while TEGDMA was found in Eagle Spectrum and Greengloo.

TEGDMA elution from uncured samples was largely higher compared to cured ones (Fig. 4A and 4B) while there was no statistically significant difference in BisGMA elution between cured and uncured specimens (Fig. 5A and 5B).

TEGDMA release did not result to be time-dependent (Fig. 4A and 4B).
On the other hand, Bis-GMA elution resulted to be time-dependent for Eagle Spectrum (Fig. 5A) but not for Transbond XT (Fig. 5B). The highest Bis-GMA concentration was seen after $72 \mathrm{~h}$ for Eagle Spectrum (0.08 $\left.\mathrm{mmol} \mathrm{L}^{-1}\right)$ (Fig. 5A).

\section{Discussion}

The introduction of RBDM in the orthodontic clinical practice is well established due to their easy handling. To date many studies focused on their physical properties, such as shear bond strength (Finnema et al., 2010), with less emphasis on RBDM biocompatibility, despite the proximity of their application site to the periodontal tissues which may cause inflammation of gingiva, oral mucosa and alveolar bone (Borra et al., 2009).

Different studies, dealing with RBDM biocompatibility, are based on in vitro tests because of the ability to control the environment and cellular 
responses (Jagdish et al., 2009; Franz et al., 2003; Malkoc et al., 2010). According to the strategies for material testing, presented by Wataha (2012), the purpose of our study, was to determine in vitro material liability, the dynamics of any component release and the potential of released monomers to alter cell metabolism and function. Polymerization and monomer conversion of the RBDM organic matrix is rarely fully completed and, this event seems to be responsible for most of the reported undesirable effects such as cytotoxicity, allergic and inflammatory potential (Goldberg, 2008; Borelli et al., 2017).

The effectiveness of a light-curing unit to cure a composite resin material efficiently depends on several factors, such as the wavelength of emitted light, type of photoinitiator, bulb intensity, exposure time, distance and angulation of light tip from the composite surface, type of $\mathrm{RBC}$ and shade of the resin composite (Jiménez-Planas et al., 2008; Marigo et al., 2015).

The light curing unit tip should ideally be in direct contact with the resin composite; however this is rarely clinically possible (Marigo et al., 2015; Caldas et al., 2003). In our study protocol, the tip was positioned as close as possible to the composite disk and a high intensity LED curing unit was used. The chosen curing time was the longest time suggested by the manufacturer (Table 1) in order to evaluate monomer release in the best curing conditions.

Monomer elution from dental resins mainly occurs through diffusion of the resin matrix and is, consequently, dependent on the size and the chemical composition of the leachable molecules (Gioka et al., 2005).

In our study, monomer leaching from cured and uncured orthodontic composites was evaluated through HPLC. The concentration of TEGDMA and Bis-GMA was measured in extracts of the resins, in order to evaluate the monomer release in eluates prepared in the same condition used for cell testing.

TEGDMA monomer was released significantly more from the uncured samples than from the cured ones. Moreover, among the tested materials which contain TEGDMA, Greegloo resulted to have the highest TEGDMA values that might explain its higher toxicity compared to Eagle Spectrum. On the other hand, BisGMA monomers, present in the Eagle Spectrum and Transbond XT resins, but not in Greegloo, was in an equally smaller amount from both cured and uncured samples. These results could be explained focusing on the chemical differences between the two mentioned monomers. TEGDMA is a hydrophilic monomer with a low molecular weight, therefore the unbound part of the monomer may be released in high amounts into the oral cavity or in any other aqueous environment (Geurtsen et al., 1999), whereas, Bis-GMA is a hydrophobic monomer with an higher molecular weight and, thus, only small amounts are released in the aqueous solution (Tanaka et al., 1999). Our results were in line with previous studies that demonstrated that TEGDMA was one of the most eluted monomer from various kind of resin materials (Geurtsen, 1998; Geurtsen et al., 1998). Moreover, Bis-GMA showed a time dependent release pattern from Eagle Spectrum but not from Transbond, but, in both cases, the amounts released were so small that they should not be able to affect cytotoxicity.

On the other hand, TEGDMA release was not influenced by time.

Several in vitro studies demonstrated that Bis-GMA and TEGDMA caused a dose-dependent mutagenic effect inducing formation of micronuclei, cell cycle delay and apoptosis (Schweikl et al., 1998; 2001; Heil et al., 1996; Yano et al., 2011) and may influence specific cell responses of the innate immune system (Eckhardt et al., 2009a; 2009b). Moreover TEGDMA, as well as BisGMA, is reported to affect GSH concentration (Spagnuolo et al., 2013), a natural radical scavenger, which protects cell structures from damage caused by oxidative stress (Schweikl et al., 2006). Depletion of the intracellular GSH pool may increase the intracellular ROS levels leading to cell death through oxidative damage (Spagnuolo et al., 2013; Heil et al., 1996).

In the present study, we used permanent mouse $3 \mathrm{~T} 3$ fibroblasts in order to assess the cytotoxicity of orthodontic composites, because they can be easily amplified and are available in large numbers for testing (Koliniotou-Koubia et al., 2001), furthermore this cell line is recommended for the in vitro evaluation of materials by the International Standards Organization (ISO 7405).

Cell viability was evaluated by Alamar Blue after three different exposure periods (24, 48 and $72 \mathrm{~h}$ ) because it is a non-toxic dye and this allows it to be used for continuous monitoring of cell viability (Borra et al., 2009). Our results showed that all the materials were cytotoxic and that uncured samples caused a major decrease in cell survival compared to cured ones. Tested materials caused different decrease in cell viability and this might be justified by the differences in chemical composition (Table 1). The highest reduction in cell viability was caused by the Greengloo, which was found to release a major amount of TEGDMA compared to Eagle Spectrum, in particular when uncured. Taken together, these observations indicated that TEGDMA might be the main causative factor of the severe cytotoxic effects determined by Greengloo eluates, but our results cannot exclude that different molecules, not included in our investigation, could contribute to the cytotoxic response exerted by this composite. TEGDMA toxicity is mainly related to the highest monomer release in the oral cavity; many studies 
demonstrated that Bis-GMA molecules, tasted alone, showed a greater intrinsic toxicity compared to TEGDMA monomers (Schweikl et al., 1998), but it show less toxicity when combined with others molecules and this could be justify the differences in our toxicity result between Grengloo (TEGDMA) and Eagle Spectrum (TEGDMA and Bis-GMA). The causes of this agonistic or antagonistic behavior remain unknown (Schuster et al., 2000). However, the composite tested in which the major monomers was Bis-GMA (Transbond XT and Eagle Spectrum) exerted less toxicity in both experimental conditions (cured and uncured) and this could be related to the small amount of monomer present and released.

\section{Conclusion}

- This study illustrated that cured and uncured orthodontic composites can exert a cytotoxic effect. Not all the composites affected cell viability to the same extent

- Resin curing was shown to play a key role in determining cell toxicity: Our result suggested that the differences in chemical composition of resin matrix much more than the amount of monomer leaching from orthodontic resins appeared to be related to the decrease in cell viability in this in vitro study

- Practitioners should pay crucial attention to resin polymerization after bracket placement, because extensive monomer release due to inaccurate curing could play a synergic role in affecting RBDM biocompatibility

\section{Acknowledgment}

The authors are grateful to Dr. Roberto Rongo of the University of Naples "Federico II" for his support for statistical analysis and acknowledge the 3M Unitek, Micerium S.p.a. and Ormco Europe for providing materials.

\section{Author's Contributions}

All authors read and approved the final manuscript.

Roberto Uomo: Performed cytotoxicity experiments, collected and analyzed data, drafted the manuscript and prepared it for submission.

Gianrico Spagnuolo: Designed the study, analyzed and interpreted data, wrote the paper and critically revised it.

Giuseppina Nocca: Designed and performed HPLC experiments, wrote the paper.

Rosa Valletta, Ambrosina Michelotti and Angela Galeotti: Supervised the project and revised the manuscript critically.
Vincenzo D'Antò: Designed the study, interpreted the data, wrote and critically revised the paper.

\section{Conflict of Interest}

The authors disclose any financial, personal or other associations that may influence or be perceived to influence, their work.

\section{References}

Borelli, B., F. Zarone, V. Rivieccio, F. Riccitiello and M. Simeone et al., 2017. Polyacrylic resins regulate transcriptional control of interleukin-6, gp80 and gp130 genes in human gingival fibroblasts. J. Oral Sci., 59: 87-91. DOI: 10.2334/josnusd.16-0388

Borra, R.C., M.A. Lotufo, S.M. Gagioti, M. Barros Fde and P.M. Andrade, 2009. A simple method to measure cell viability in proliferation and cytotoxicity assays. Braz. Oral Res., 23: 255-262. DOI: $10.1590 / \mathrm{S} 1806-83242009000300006$

Buonocore, M.G., 1955. A simple method of increasing the adhesion of acrylic filling materials to enamel surfaces. J. Dent. Res., 34: 849-53. DOI: $10.1177 / 00220345550340060801$

Caldas, D.B., J.B. de Almeida, L. Correr-Sobrinho, M.A. Sinhoreti and S. Consani, 2003. Influence of curing tip distance on resin composite Knoop hardness number, using three different light curing units. Oper. Dent., 28: 315-20. PMID: 12760705

D'Antò, V., G. Spagnuolo, I. Polito, S. Paduano and L. Ambrosio, 2009. Valletta R. In vitro cytotoxicity of orthodontic primers. Prog. Orthod., 10: 4-11. PMID: 19506741

Eckhardt, A., N. Gerstmayr, K.A. Hiller, C. Bolay and C. Waha et al., 2009. TEGDMA-induced oxidative DNA damage and activation of ATM and MAP kinases. Biomaterials, 30: 2006-2014.

DOI: $10.1016 /$ j.biomaterials.2008.12.045

Eckhardt, A., T. Harorli, J. Limtanyakul, K.A. Hiller and C. Bosl et al., 2009. Inhibition of cytokine and surface antigen expression in LPS-stimulated murine macrophages by triethylene glycol dimethacrylate. Biomaterials, 30: 1665-1674. DOI: 10.1016/j.biomaterials.2008.09.024

Finnema, K.J., M. Ozcan, W.J. Post, Y. Ren and P.U. Dijkstra, 2010. In-vitro orthodontic bond strength testing: A systematic review and metaanalysis. Am. J. Orthod. Dentofacial Orthop., 137: 615-622. DOI: 10.1016/j.ajodo.2009.12.021

Franz, A., F. König, M. Anglmayer, X. Rausch-Fan and G. Gille et al., 2003. Cytotoxic effects of packable and nonpackable dental composites. Dent. Mater., 19: 382-392.

DOI: $10.1016 / \mathrm{S} 0109-5641(02) 00081-7$ 
Geurtsen, W., 1998. Substances released from dental resin composites and glass ionomer cements. Eur. J. Oral. Sci., 106: 687-95.

DOI: 10.1046/j.0909-8836.1998.eos10602ii04.x

Geurtsen, W., F. Lehmann, W. Spahl and G. Leyhausen, 1998. Cytotoxicity of 35 dental resin composite monomers/additives in permanent $3 \mathrm{~T} 3$ and three human primary fibroblast cultures. J. Biomed. Mat. Res., 41: 474-80. DOI: 10.1002/(SICI)10974636(19980905)41:3<474::AID-JBM18>3.0.CO;2-I

Geurtsen, W., W. Spahl, K. Müller and G. Leyhausen, 1999. Aqueous extracts from dentin adhesives contain cytotoxic chemicals. J. Biomed. Mater. Res., 48: 772-777. DOI: 10.1002/(SICI)10974636(1999)48:6<772::AID-JBM2>3.0.CO;2-X

Gioka, C., C. Bourauel, A. Hiskia, D. Kletsas and T. Eliades et al., 2005. Light-cured or chemically cured orthodontic adhesive resins? A selection based on the degree of cure, monomer leaching and cytotoxicity. Am. J. Orthod. Dentofacial Orthop., 127: 413-419. DOI: 10.1016/j.ajodo.2004.02.015

Goldberg, M., 2008. In vitro and in vivo studies on the toxicity of dental resin components: A review. Clin. Oral Invest., 12: 1-8.

DOI: $10.1007 / \mathrm{s} 00784-007-0162-8$

Heil, J., G. Reifferscheid, P. Waldmann, G. Leyhausen and W. Geurtsen, 1996. Genotoxicity of dental materials. Mutat. Res., 368: 181-194.

DOI: $10.1016 / \mathrm{S} 0165-1218(96) 90060-9$

Jagdish, N., S. Padmanabhan, A.B. Chitharanjan, J. Revathi and G. Palani et al., 2009. Cytotoxicity and degree of conversion of orthodontic adhesives. Angle Orthod., 79: 1133-1138. DOI: 10.2319/080808-418R.1

Jiménez-Planas, A., J. Martin, C. Abalos and R. Llamas, 2008. Developments in polymerization lamps. Quintessence Int., 39: e74-e84. PMID: 18560645

Jonke, E., A. Franz, J. Freudenthaler, F. König and H.P. Bantleon et al., 2008. Cytotoxicity and shear bond strength of four orthodontic adhesive systems. Eur. J. Orthod., 30: 495-502. DOI: 10.1093/ejo/cjn042

Koliniotou-Koubia, E., P. Dionysopoulos, E.A. Koulaouzidou, A.H. Kortsaris and Y. Papadogiannis, 2001. In vitro cytotoxicity of six dentin bonding agents. J. Oral. Rehabil., 28: 971-975.

PMID: 11737570

Malkoc, S., B. Corekci, H.E. Ulker, M. Yalçin and A. Sengün, 2010. Cytotoxic effects of orthodontic composites. Angle Orthod., 80: 571-576. DOI: $10.2319 / 092809-537.1$

Marigo, L., G. Spagnuolo, F. Malara, G.E. Martorana and M. Cordaro et al., 2015. Relation between conversion degree and cytotoxicity of a flowable bulk-fill and three conventional flowable resincomposites. Eur. Rev. Med. Pharmacol. Sci., 19: 4469-4480. PMID: 26698240
Newman, G.V., 1992. First direct bonding in orthodontia. Am. J. Orthod. Dentofacial Orthop., 101: 190-191.

DOI: $10.1016 / \mathrm{S} 0889-5406(05) 80242-2$

Schuster, G.S., G.B. Caughman and F.A. Rueggeberg, 2000. Changes in cell phospholipid metabolism in vitro in the presence of HEMA and its degradation products. Dent. Mater., 16: 297-302.

DOI: 10.1016/S0109-5641(00)00022-1

Schweikl, H., G. Schmalz and K. Rackebrandt, 1998. The mutagenic activity of unpolymerized resin monomers in Salmonella typhimurium and V79 cells. Mutat. Res., 415: 119-30.

DOI: $10.1016 / \mathrm{S} 1383-5718(98) 00067-9$

Schweikl, H., G. Schmalz and T. Spruss, 2001. The induction of micronuclei in vitro by unpolymerized resin monomers. J. Dent. Res., 80: 1615-20.

DOI: $10.1177 / 00220345010800070401$

Schweikl, H., G. Spagnuolo and G. Schmalz, 2006. Genetic and cellular toxicology of dental resin monomers. J. Dent. Res., 85: 870-877. DOI: $10.1177 / 154405910608501001$

Schweikl, H., K.A. Hiller, C. Bolay, M. Kreissl and W. Kreismann et al., 2005. Cytotoxic and mutagenic effects of dental composite materials. Biomaterials, 26: 1713-1719.

DOI: 10.1016/j.biomaterials.2004.05.025

Spagnuolo, G., C. Desiderio, V. Rivieccio, M. Amato and D.V. Rossetti et al., 2013. In vitro cellular detoxification of triethylene glycol dimethacrylate by adduct formation with $\mathrm{N}$-acetylcysteine. Dent. Mater., 29: e153-160.

DOI: 10.1016/j.dental.2013.04.023

Suh, B.I., 2004. Oxygen-inhibited layer in adhesion dentistry. J. Adhes Dent., 16: 316-323. DOI: $10.1111 /$ j.1708-8240.2004.tb00060.x

Tanaka, K., M. Taira, H. Shintani, K. Wakasa and M. Yamaki, 1991. Residual monomers (TEGDMA and Bis-GMA) of a set visible-light-cured dental composite resin when immersed in water. J. Oral. Rehabil., 18: 353-362.

DOI: $10.1111 / \mathrm{j} .1365-2842.1991 . t b 00067 . x$

Wataha, J.C., 2012. Predicting clinical biological responses to dental materials. Dent. Mater., 28: 23-40. DOI: $10.1016 /$ j.dental.2011.08.595

Yano, J., C. Kitamura, T. Nishihara, M. Tokuda and A. Washio et al., 2011. Apoptosis and survivability of human dental pulp cells under exposure to BisGMA. J. Applied Oral Sci., 19: 218-222. DOI: $10.1590 / \mathrm{S} 1678-77572011000300007$ 